\title{
De casa para o meio-fio: pequenas histórias de uma residência terapêutica
}

\author{
Mario Cesar Carvalho de Moura Candido, (DD I, ${ }^{\star}$ Maria Cristina Campello Lavrador, (D) II Rafaela Gomes Amorim, (D) II \\ ${ }^{I}$ Universidade Federal Fluminense, Niterói, RJ, Brasil \\ II Universidade Federal do Espírito Santo, Vitória, ES, Brasil
}

\begin{abstract}
Resumo
Estes escritos versam sobre figuras do cotidiano de ex-internos de um hospital psiquiátrico em uma residência terapêutica na cidade de Vitória-ES. Após anos de isolamento manicomial, seus moradores e parceiros criam caminhos comuns de uma vida em liberdade, abrindo-se à imprevisibilidade das relações sociais, temporais, afetivas etc., que se dão no espaço comunitário, bem como às lutas e resistências diante dos mecanismos biopoliticos de normalização. Foram utilizados registros em caderno de campo como ferramenta metodológica, inspirando a produção de pequenas narrativas, fragmentos de histórias, que compõem e ativam o fluxo de experiências associadas à reforma psiquiátrica e à luta antimanicomial, com o objetivo de contribuir para uma manutenção das conquistas desse campo e também para o avanço desses processos. Os resultados apontam para a produção de um cuidado em saúde mental indissociável de uma dimensão ético-estético-política, afirmando práticas de potencialização de liberdades, buscando afetações e trocas com outras formas de sociabilidade.
\end{abstract}

Palavras-chave: saúde mental; cotidiano; reforma psiquiátrica.

\section{From the house to the sidewalk: tales of a therapeutical residence}

\section{Abstract}

This research approaches aspects of the everyday life in a therapeutical residence in Vitória, Espirito Santo state, Brazil. The residence is part of a social policy known for sheltering people who have been subject to a long permanence in a psychiatric hospital located in a nearby municipality. After years of isolation, chronicle abuse and permanent seclusion, the residents and their partners create common paths towards freedom and other possibilities of experience inside the house and in the city, opening themselves to unknown social exchanges and also to the many possible resistences against biopolitical investments over life. The experiences related to the research were registered in field notebooks, which inspired the production of small narratives that reinforce the struggles related to the psychiatric reform, aiming to contribute to it s development. The results show the importance of care in mental health, which must be made considering ethical, estethical and political dimensions, reinforcing freedom, encounters and multiple forms of sociability.

Keywords: mental health; everyday life; psychiatry reform.

\section{Narrar o "inútil"}

Após o café e a chegada de um amigo, o homem resolve sair de casa. Decidido, ele solicita a abertura do portão, substituindo os balbucios de todo dia por voz clara e assertiva.

Na rua, caminha com dificuldade, mas não desanima. Transforma um trajeto simples e rápido, ordinário, em demorado saboreio de cumprimentos, toques nos muros das casas e vento.

E num ritmo contrário ao frenesi de buzinas e gente apressada, ele encontra uma praça deserta. Ali, o caminhar se faz ainda mais lento e o corpo vai se curvando vagarosamente ao encontro da grama.

Com fluidez e maestria, abraça o chão verde, luminoso sob o sol das dez. E, feito lagarto, rasteja até a fronteira da praça com a rua. De lado, que nem César ou Adriano, observa a vida de novo ângulo, e conta: 4 carros; 2 motos; 3 casas; 1 mulher; 3 árvores. E assim prossegue no inventário das coisas todas.

Revigorado, inclui a si e ao amigo no cômputo do espólio.

E, por fim, se levanta. Em seu corpo um véu de cal, grama

^Endereço para correspondência: Universidade Federal Fluminense, Instituto de Psicologia, Campus do Gragoatá. Rua Professor Marcos Waldemar de Freitas Reis, s/no ${ }^{\circ}$, Bloco N, $4^{\circ}$ andar. São Domingos - Niterói, RJ - Brasil. CEP: $24210-$ 201.Emails: mariocesar.candido@gmail.com, cris.campello02@gmail.com, psi.rafaela@gmail.com

Os dados completos dos autores encontram-se ao final do artigo. e sujeira. Já era hora do almoço ${ }^{1}$.

Este trabalho versa sobre as relações de moradores de residências terapêuticas, ex-internos de um hospital psiquiátrico, com as matérias da cidade. Após anos de internamento e de vida institucionalizada, propomos caminhar com eles, em parceria, na construção de um novo cotidiano/corpo que vai se traçando entre uma casa, ruas, praças e parques.

Os Serviços Residenciais Terapêuticos, também conhecidos como Residências Terapêuticas, são locais de moradia destinados, dentre outros casos, a pessoas que vivenciaram longas internações psiquiátricas (anos ou décadas) e que por isso mesmo encontram-se em dificuldade de restaurar os laços sociais que mantinham antes do período de internação (BRASIL, 2004). As residências, junto aos outros equipamentos de saúde e cuidado instituídos pela rede de atenção psicossocial, constituem ferramentas importantes para a manutenção das conquistas da luta antimanicomial.

Diante disso, seja nos serviços substitutivos ao modelo manicomial, seja na infinidade de misturas e encontros produzidos na cidade, o que se coloca como problema é a possibilidade da produção de uma abertura para o imprevisível, uma aposta em misturas e composições capazes

$1 \mathrm{O}$ texto será povoado por pequenas narrativas em itálico. Elas foram inspiradas em cadernos de campo produzidos ao longo da pesquisa e se referem a experiências tecidas no âmbito desta. 
de desnaturalizar a loucura como negativo da razão e a vida de todo dia como o lugar da repetição de padrões naturalizados, bem como tantos outros registros cotidianos, automatismos nos modos de vida nestes tempos em que construímos morada.

Esta pesquisa foi realizada em Vitória-ES. O enfoque se faz sobre as formas de relação e os usos que os antigos internos do hospital psiquiátrico e seus parceiros são capazes de construir dentro dos elementos comunitários em que se situam e, sobretudo, na imprevisibilidade das relações sociais, temporais, afetivas, estéticas etc., que se dão no espaço da cidade. Tais relações, acreditamos, são capazes de disparar interferências nos modos de vida serializados pela razão, pelo Estado e seus aparatos de controle, abrindo novos universos de sentidos, intercessões na construção de um mundo comum.

Diante deste desafio apostamos em narrativas do ínfimo, filigranas de um cotidiano que compõem paisagens de ricas pequenezas. Longe dos grandes discursos que proclamam a verdade da loucura ou qualquer outra verdade, vemos nestas curtas histórias alguns vestígios para a composição de caminhos que, tomando a intercessão entre arte, clínica e vida, misturam-nas e as confundem até o ponto de não mais podermos distingui-las.

Histórias estas que propõem caminhos de abertura que embaralham os territórios conhecidos, inclusive os da loucura, e apontam para outras formas de estar na vida. Neste sentido, cabe traçar algumas considerações sobre a escrita como importante ferramenta nesta empreitada.

Preocupado com os rumos da vida moderna a partir da evolução das forças produtivas, Benjamin (1985) destaca uma figura: o narrador. Para ele, "as ações da experiência estão em baixa, e tudo indica que continuarão caindo até que seu valor desapareça de todo" (BENJAMIN, 1985, p. 198). Essa experiência de que trata o autor é aquela que se passa de pessoa para pessoa por meio do registro narrativo; experiências comunicáveis assemelhadas à tradição oral que carregam consigo as centelhas do conselho e da sabedoria.

Para Benjamin (1985, p. 200) "aconselhar é menos responder a uma pergunta do que fazer uma sugestão sobre a continuação de uma história. [...] O conselho tecido na substância viva da existência tem um nome: sabedoria". Experiência plástica esta da narrativa, pois sempre incita narrador e ouvinte a um exercício criativo de engendramento corajoso de um porvir.

O tecido de que é feito a narrativa é a experiência do narrador ou de outros, que é sempre enxertada na própria experiência de quem ouve. Via de mão dupla, produção no seio de um "entre" si e outro(s). Portanto a narrativa é viva: "Ela não está interessada em transmitir o "puro em-si" da coisa narrada como uma informação ou um relatório. Ela mergulha a coisa na vida do narrador para em seguida retirá-la dele" (BENJAMIN, 1985, p. 205). Ela não conserva o rosto inerte de uma univocidade de sentido, servindo de ferramenta para um processo que vai tecendo outras relações, sentidos e mundos.
Desta forma, Ferreira (2011, p. 127) aponta que as contribuições de Walter Benjamin podem nos ajudar a realizar uma discussão teórico-metodológica "sobre a raridade dos vínculos entre as experiências dos homens contemporâneos, em que o isolamento e a individualização não permitem um compartilhamento de destinos". Por meio da atividade narrativa, segue o autor, estaríamos abrindo espaço também para a identificação dos "fios que se remetem a uma possibilidade de presente que não é o nosso" (FERREIRA, 2011, p. 128), alargando as fronteiras e ampliando os caminhos de um porvir.

Narrar trata-se de um fazer eminentemente instrumental e indissociável de um labor estético. A partir deste ensinamento, ao enfatizar a dimensão de um discurso que se faz presente e vivo na constituição de nós mesmos, ousamos igualmente fazer uma aproximação com Foucault (2012), que em seu texto "A escrita de si" fala de dimensões da escrita que se aliam às reflexões propostas neste trabalho.

Antes disso, contudo, importa ressaltar que não se trata de postular uma correspondência imediata (e de certo ingênua) entre o estatuto da escrita nos trabalhos de Benjamin e Foucault. Sabemos que estes dois autores ocupam lugares distintos, que suas preocupações se diferenciavam e que escreviam em épocas bastante diferentes. Entretanto, a menção aos autores é feita na tentativa de reunir nestes dois pensamentos um aspecto que consideramos fundamental: a escrita como exercício de si mesmo, que produz um ponto de contato que nos coloca em face de uma alteridade capaz de deslocar coordenadas identitárias, abrindo outros campos de sentido.

Foucault (2004) coloca em xeque a produção de identidades dotadas de uma substancialidade fechada e por isso mesmo consideradas como leis, princípios ou códigos de existência. A produção identitária, segundo o autor, seria apenas um jogo para facilitar relações e abrir um campo de experimentações em que o "tornar-se" acaba sendo mais ou tão importante que o "ser". Neste sentido, cumpre produzir não apenas relações de identificação a um conjunto de formas dadas, mas sobretudo processos de diferenciação, de criação, que nos puxem além dos modos já conhecidos de organização da experiência vivida.

Nesta tarefa, que por sinal é hercúlea, fiamo-nos também na ousadia intelectual de Deleuze (2010) ao afirmar que uma teoria é como uma caixa de ferramentas destinada a um uso, a uma serventia. Esta "caixa" se situa no interior das estratégias de luta contra as pretensões de totalização dos saberes contemporâneos.

Neste aspecto, Deleuze (2010, p. 71) nos diz: “É o poder que por natureza opera totalizações.” Esta afirmação se situa na direção de uma crítica que visa reorientar o papel das teorias que movimentam os campos discursivos. Estas, ao invés de postularem um determinismo ancorado em seus postulados essencialistas, necessitariam se conectar aos imperativos dos usos e efeitos que produzem junto aos sujeitos a que se destinam. Continua o autor: "A teoria não totaliza; a teoria se multiplica e multiplica” (DELEUZE, 2010, p. 71). É neste sentido que 
cumpre denunciar as totalizações, fazendo-o por meio da produção de conexões entre os sistemas de pensamento e as demandas colocadas pelo presente.

Aqui, portanto, as contribuições dos referidos autores são tomadas como ferramentas na tessitura de uma pesquisa que busca afirmar a vida em suas diferentes formas e composições.

Uma destas ferramentas é, sem dúvida, a escrita de si. Foucault (2012) destaca a importância da escrita como artifício na elaboração e exercício das técnicas de si nos primeiros séculos da era cristã. A "escrita de si mesmo" (FOUCAULT, 2012, p. 141) parece constituir papel central em meio às recomendações de exercícios que caracterizavam as práticas de ascese no contexto das escolas filosóficas estóica e epicurista, ambas importantes disseminadoras do que o autor caracterizará como a "cultura de si" (FOUCAULT, 1985, p. 43).

A chave para a compreensão desta cultura e de seus efeitos parte de uma análise detida de documentos escritos que assumiam formas diversas, mas mantinham em comum, segundo uma expressão de Plutarco utilizada por Foucault, uma "função etopoiética" (FOUCAULT, 2012, p. 144). Tal função consistiria na operação, realizada pela via da escrita, que transforma certos conjuntos de preceitos e regras abstratas em princípios racionais de ação. Em outras palavras, o que se opera na atividade de escrita seria a transformação de uma "verdade" (aqui concebida como conjunto de prescrições de ordem geral) em "ethos" (uma forma singular e aberta de relação com os dados preceitos).

No contexto de uma escrita etopoiética, Foucault (2012) cita a produção de registros pessoais de dados e acontecimentos cotidianos: os hypomnêmata. Nas palavras do filósofo:

Ali se anotavam citações, fragmentos de obras, exemplos e ações que foram testemunhadas ou cuja narrativa havia sido lida, reflexões ou pensamentos ouvidos ou que vieram à mente. Eles constituíam uma memória material das coisas lidas, ouvidas ou pensadas; assim, eram oferecidos como um tesouro acumulado para releitura e meditação posteriores (FOUCAULT, 2012, p. 144).

Estes registros não funcionavam segundo o modelo confessional ou catártico de certas formas de diários românticos e nem constituíam simples suportes de memória; seu funcionamento, isto sim, estava estreitamente vinculado a uma dimensão de exercício ligada à leitura, releitura, meditação, conversa consigo mesmo e com outros etc. $\mathrm{O}$ que estava contido nos hypomnêmata não eram segredos do homem, mas um suporte material para a constituição de si mesmo.

Fala-se, portanto, de um discurso que se encontra em íntimo liame com a vida; de uma arte da escrita que desemboca na arte da constituição de si. Processo que gera formas singulares de apropriação de elementos heterogêneos que se apresentam na forma dos discursos que povoam corpos e modos de vida. Segundo Foucault (2012, p. 148):

A escrita como exercício pessoal feito por si e para si é uma arte da verdade díspar; ou, mais precisamente, uma maneira racional de combinar a autoridade tradicional da coisa já dita com a singularidade da verdade que nela se afirma e a particularidade das circunstâncias que determinam seu uso.

Produzir uma arte da verdade díspar por meio da escrita é permitir que esta se embriague de cheiros, sabores, cores; é atuar sobre o mundo a partir de seus inúmeros elementos, multiplicando-os em novos arranjos e abrindo espaço para o impensado na forma de um ethos.

A pesquisa que se descreve aqui seria inconcebível sem o movimento cotidiano de registros das experiências no campo de trabalho proposto, movimento que se dá com a confecção de cadernos de campo que, quem sabe um pouco inspirados na forma dos hypomnêmata, buscam reunir elementos de uma experiência, fragmentos que unem numa mesma página e num mesmo fluxo de escrita diferentes pessoas, lugares, atribuições, discursos...

Com isso tudo talvez seja possível ativar uma rede que fala não apenas de uma pesquisa, mas também da vida. Nesses cadernos o que se propõe é uma reunião de pedaços de cotidiano capazes de, juntos, constituírem um "corpo" (FOUCAULT, 2012, p. 148) de sentidos sobre o qual seja possível operar inflexões necessárias nos modos de enxergar a loucura, bem como nas formas serializadas de estar que apagam ou esmaecem as potências estéticas do viver junto.

Desta forma, os registros feitos em caderno de campo constituem uma memória material e viva das coisas lidas, ouvidas, pensadas, vividas. É a partir desta "memória" - substrato material de fragmentos de vivências que se carregam na pele - que talvez seja possível construir um "corpo" cujas formas e nuances serão dadas pela elaboração de breves narrativas. Com este exercício visa-se colocar em questão a multiplicidade de elementos que configuram esta experiência que chamamos de pesquisa.

Aqui destacamos a indagação feita por Benjamin (1985), que se pergunta se a relação entre o narrador e sua matéria, a vida, não seria de caráter artesanal, fazendo-o trabalhar de modo a produzir outras formas (sólidas, líquidas, gasosas...) no desafio da construção de um presente.

Assim, a narrativa como ferramenta, enfatizamos mais uma vez, não fornece respostas prontas, fechadas, mas faz ecoar no mundo a experiência que talvez nos lance no exercício de nós mesmos e de nossas práticas. Ela provoca algo como um "ensaiar" de nós mesmos que escapa de toda funcionalidade prévia ou idealidade especulativa.

Um "ensaiar" que se faz à revelia de qualquer pretensão de totalidade; que trabalha a partir de matérias de corpos e vidas que se espalham sem pedir licença e constituem o campo no qual algo emerge em ato. Um ensaio que não se submete a regras prévias, pronto a abrir um espaço que cria.

Narrar o "inútil" comporta, entretanto, um evidente paradoxo. Se cremos ser importante trazer luz às pequenas histórias do cotidiano, não estaríamos provendo-as de uma necessária utilidade? Nossa resposta é afirmativa: o "inútil" é de fato bastante útil. Contudo, reforçamos a aposta ética de que o paradoxo acima é a maior expressão: em um mundo povoado por finalidades pré-concebidas, utilitarismos ordinários, tecnicismos sufocantes, 
especialismos fragmentados e "fins" de todo tipo, não seria importante reabilitar a experiência singular de encontros anônimos, pequenos, menores, "inúteis"? E talvez assim escapar, mesmo que parcialmente, às armadilhas de controle e normalização que sagram estes tempos?

Acreditamos que a perspectiva aqui narrada possa contribuir para abrir caminhos em cuja intercessão despontem outros modos de estar, viver, imaginar: um fazer clínico, artístico e vital.

No parque éramos muitos. Espalhados, diminuíamos o espaço entre nós e o mundo de cores, flores, folhas, terra. Mas, no instante de um cuidado, noto uma ausência. Nada de pânico, penso. Espero.

Afasto-me de meus companheiros e vejo um grupo de crianças. Muitas, barulhentas, brincalhonas. Lancheiras abertas, hora do lanche. Em pé altivamente estava a professora, explicando com gestos imensos e voz alta algum sei-lá-o-quê. Em meio às crianças, sem cerimônia, lá estava ele acocorado comendo um pão.

Chego na hora. "Quem é você?" Pergunta a professora ao novo "aluno". Ele sorri aquele sorriso sem dentes e cheio de cara. Eu me aproximo e a pergunta se dirige a mim: "quem é ele?".

"Ele é o Chico e eu sou o Mario", respondo.

"Sejam bem-vindos Chico e Mario", ela diz. E alguma criança me oferece um pão.

Chico, acocorado em meio às crianças, parece viver um encontro único e especial; as crianças, surpreendidas por uma visita inesperada, também experimentam o rumor simples e leve de uma curiosidade; e, por fim, o pão que é oferecido talvez seja um convite a explorar as possibilidades éticas, estéticas e políticas dos fazeres que povoam o campo de nossas inquietações.

Possibilidades múltiplas que se conectam a um rigor ético-estético-político (ROLNIK, 1993), que passa ao largo das prescrições de ordem universalizante (conjuntos de regras ou verdades intocáveis), buscando uma ética que permita a construção de relações que nos convoquem à criação (estética) a partir de vestígios de um cotidiano, constituindo um campo político de ação em favor dos encontros, afetações e trocas entre os mais diversos atores sociais.

\section{As pequenas histórias}

Os dizeres que aqui se desenrolam são capturáveis apenas em movimento. Um movimento lento que vai de mansinho entrando em uma casa, abrindo portas, percorrendo espaços, recolhendo afetações. Para então, vagarosamente, se dirigir ao ponto de onde entrou, abrindo novamente o portão velho e enferrujado, pisando com cuidado no chão sujo de um meio-fio, em direção à rua.

Este movimento pode se repetir muitas vezes, mais rápido ou mais lento, intencional ou não. Contudo, o que importa é o seguinte: é no apagamento nebuloso das demarcações rígidas entre uma casa e uma rua que se produzem algumas possíveis análises. Isto porque este apagamento nada mais é do que a possibilidade da aber- tura de uma experimentação ética que nos leve um pouco mais além de tudo o que temos vivido até hoje, no campo da saúde mental e também nas vidas que temos cunhado juntos em uma cidade. Isto exige presença e alianças ritmadas por intrusivos desassossegos. E implica, ainda, uma certa confissão de ignorância.

Já da esquina oposta ouvia-se um som precário. Mais à frente, na calçada da casa amarela, via-se um homem sentado num banco, dedilhando notas de um violão velho. Ao me ver, levanta como de costume. Após um cumprimento cavalheiro, oferece o violão. "Mas eu não sei tocar", digo. E ele retruca: "Não precisa saber, seu bobo. É só fazer assim, ó..." E movimenta os dedos por entre as cordas frouxas, e bate com a palma da mão na madeira lisa, entoando um batuque legal.

É bem verdade que não há apenas uma forma de tocar violão, ainda mais um violão sem cordas. Quer dizer, haveria, sim, uma única forma: aquela imposta por uma dimensão de saber encarcerada em seus esquemas a priori, em seus códigos impositivos que nos dizem qual é a "melhor" forma de tocar tal ou qual instrumento.

Bem, talvez seja preciso dizer que um violão tocado à moda tradicional também tenha a sua beleza e o seu valor; não é isso que se questiona. Contudo, é bem possível produzir com ele outros sons e outros usos, não referenciados a um conjunto de regras abstratas a serem docilmente aplicadas ao seu objeto.

Mas por que o violão sem corda? O relato acima é compartilhado em razão do estranhamento absoluto que produziu neste "pesquisador". O que salta aos olhos é a recusa peremptória em tomar o violão nos braços, recusa esta produzida em razão da falta de um suposto "saber": não sei aplicar o conjunto de regras universais utilizadas para “bem” tocar um violão, logo, de nada adiantaria segurá-lo.

Trata-se de uma concepção de saber que aqui assume um caráter paralisante, anulando a experiência ou prescindindo dela. Melhor seria, quem sabe, lançar-se à brincadeira da produção de sons e batuques livres da tirania dos códigos eruditos; segurar o violão e dedilhar suas linhas frouxas e bater no casco oco, aprendendo com ele, e desta vez produzindo uma forma de saber ligada a uma experiência do fazer.

Assim, deixa-se em suspenso os esquemas universalizantes do conhecer para escutar com atenção e cuidado o zumbido dos acontecimentos que irrompem da experiência, ela mesma já uma forma de intervenção.

Tarefa difícil! Ainda mais quando se está acostumado às "receitas de bolo" que "alimentam" tantos saberes das ciências humanas... Neste contexto, muito preciosa é a aparição de violões sem corda e seus corajosos tocadores...

A seguir se desenvolvem algumas pequenas, "inúteis" histórias. Em cada uma delas o que se destaca é o teor de entrelaçamento entre experiências vividas e algumas ferramentas conceituais. Com isso, almeja-se produzir uma canção aberta, feita de retalhos de instrumentos e usos imprevistos, tipo aquela improvisada na calçada da casa amarela. 
Numa sala de estar há dois sofás, um em frente ao outro. No meio, uma pequena mesa de centro. Pregada à parede lateral há uma televisão, em cuja tela chamuscada passava um programa matinal. De um lado da sala, quatro mulheres sentadas confortavelmente esperam o café oferecido pelos moradores daquela casa. Do outro lado, no outro sofá, alguns moradores da casa e seus "agregados". "Bom, estamos aqui para conversar sobre o serviço residencial terapêutico", diz um dos agregados, e continua: "queremos esclarecer algumas dúvidas que a comunidade possa ter, já que muitos vizinhos têm reclamado da nossa presença". E o discurso se intercala entre um lado e outro do sofá. O tom era de explicação, as falas são contidas, os silêncios grandes. Enquanto isso, Ana Maria Braga ensinava a fazer um bolo.

Naquela sala operou-se uma clivagem. De um lado, membros da comunidade preocupados com a recente instalação de uma "casa de loucos" nas redondezas de suas vidas; de outro, moradores daquela casa e seus "agregados": acompanhantes terapêuticos e cuidadores. Os dois polos muito bem identificados, lugares "precisos" dentro de uma lógica binária.

Importante afirmar que aquele era um encontro importante e até mesmo necessário (a relação com as comunidades ao redor das casas é quase sempre muito problemática, o que requer cuidado e atenção às possibilidades de contato). Ainda assim, foi impossível disfarçar um certo incômodo: uma sensação de que talvez aquele diálogo não estivesse operando sentidos comuns para os dois polos da conversa.

Mas talvez o problema estivesse justamente nos dois polos, naquelas duas polaridades constituídas e reforçadas no modo de produzir aquele encontro: a "comunidade" de um lado, com suas demandas, pré-concepções e afetos - o bloco-comunidade; e, do outro lado, usuários e profissionais de um equipamento de saúde mental - o bloco-residência.

Reforçamos, mais uma vez, que a produção daquele encontro dual se fez importante, mas desde que o encarássemos como ponto de partida para produções-outras, indo além dos lugares instituídos, rígidos, liberando a possibilidade de uma abertura a forças de criação conjunta.

Desta forma, a insistência sobre uma visão polarizada e polarizante em torno de formas instituídas corrobora uma visão de pesquisa (e de mundo) similar ao que Rocha e Aguiar (2003) qualificam de totalizadora, hábil a "descortinar" um funcionamento oculto, um fundamento último das coisas e dos acontecimentos, como se estes não estivessem mergulhados em forças e tensões historicamente situadas.

Neste sentido situa-se o incômodo de que se falava acima. Para além de uma dialética dos blocos, torna-se importante a construção de sentidos comuns no corpo da história. Além disso, o reforçamento de uma visão totalizante pode levar a uma busca por uma unidade ou síntese pacífica entre elementos pré-definidos, reforçando posições que afirmam uma hierarquia entre, de um lado, os possuidores de um saber, de um código (o especialista), e de outro os "alienados" deste saber.
Faz-se necessário, portanto, abrir caminho para produções coletivas que escapem dos grandes blocos tiranos dos saberes que circunscrevem as práticas sociais a lugares de "saber" e "não-saber" pacificados, que em sua docilidade inquestionada e acrítica contribuem para uma perspectiva de imposição de ideais de normatividade social que atuam conforme dispositivos de controle e esquadrinhamento das formas de vida. Dispositivos que localizamos conceitualmente no pensamento de Foucault (2010a), correspondendo a um conjunto de elementos heterogêneos os mais diversos (discursos, instituições, leis, regulamentos, especialidades, enunciações científicas e filosóficas, maneiras de organização do espaço, modos de fazer, formas de uso de determinados objetos etc.), ditos e não ditos, que funcionam em rede e podem favorecer a consecução de determinados "fins estratégicos dominantes" (FOUCAULT, 2010a, p. 244). Estes fins podem materializar-se no asseguramento de uma ordem econômica ou cultural, na manutenção de privilégios sectários, na elaboração de mecanismos de controle e normalização segundo critérios preestabelecidos, dentre outros.

Foucault (2010a) exemplifica como uma massa de população não absorvida pelos imperativos de uma economia mercantil foi sendo aos poucos reagrupada segundo as prescrições do dispositivo de controle-dominação da loucura, que até hoje segue orientando muitas práticas no campo das políticas públicas. Importa ressaltar, contudo, que entre os muitos elementos constituintes de um tal dispositivo há um certo tipo de jogo, relações muitas vezes imprevistas, mudanças de posicionamento que abrem perspectivas importantes para pensar sobre formas de resistir à dominância destes fins estratégicos gerais. Sendo assim, um dispositivo pode comportar tanto formas de dominação quanto exercícios de liberdade, tudo dependendo da forma como ele é apropriado pelos atores sociais em luta.

Aqui seria importante precisar o que queremos dizer ao evocar a problemática dos mecanismos de normalização social. Se pretendemos pensar diferente e abrir espaço para afetações e histórias em comum, pode ser de grande valia trazer algumas notas que buscam pensar sobre o cenário que nos constitui e que também constituímos com nossas práticas. Nesta tarefa pedimos mais uma vez ajuda a Michel Foucault (2010b), que debruça seu trabalho filosófico sobre rigorosas investigações históricas que julgamos capazes de apontar, quem sabe, em direção às encruzilhadas necessárias para o questionamento acerca daquilo que no presente temos nos tornado.

Em um de seus cursos dados no Collège de France, intitulado "Em defesa da sociedade", Foucault chama a atenção para o que ele definirá como um dos fenômenos fundamentais do século XIX: a emergência de uma perspectiva de poder que tomará como "objeto" o homem enquanto ser vivo, biológico, sujeito a mecanismos de controle e regulamentação que recaem sobre a vida como categoria biológica de espécie. Tal é o biopoder. No esforço de elucidar essa noção, Foucault (2010b) fará uma digressão histórica que aqui pretendemos apreender em seus aspectos mais gerais. $\mathrm{O}$ pensador aponta como, até certa altura do pensamento ocidental, prevaleceu uma 
concepção de direito centrada na figura do soberano, que com sua autoridade exercitava a máxima "fazer morrer e deixar viver" (FOUCAULT, 2010b, p. 202), o que significa dizer que seu poder concentrava-se na possibilidade de matar, um direito de soberania, de espada.

A partir do século XIX, contudo, Foucault (2010b) aponta um deslocamento importante. Gradativamente este direito de soberania vai sendo completado, sobreposto por outro. Esta segunda forma não substitui a primeira, mas vem penetrá-la, atravessá-la e também modificá-la. Vemos o surgimento, sobretudo a partir do século XIX, de um direito novo que se expressa na inversão da máxima já mencionada: trata-se do poder de "fazer viver e deixar morrer" (FOUCAULT, 2010b, p. 202).

$\mathrm{O}$ aparecimento lento e gradual deste novo direito é também uma expressão de novas tecnologias de poder surgidas um pouco antes, localizáveis, segundo Foucault (2010b), nos séculos XVII e XVIII. Centradas cada vez mais nos corpos individuais, buscavam, por meio das mais diversas técnicas, alinhá-los, classificá-los, vigiá-los e adaptá-los aos critérios de "utilidade" do nascente capitalismo mercantil e industrial. Fala-se, portanto, de uma tecnologia disciplinar do trabalho.

Entretanto, da segunda metade do século XIX em diante, observa-se um novo deslocamento. O modelo disciplinar de organização vai abrindo espaço, em seu conjunto, a uma outra tecnologia de poder que não vai, mais uma vez, excluir a antiga, mas atuar junto a ela em um plano mais amplo. Esta nova técnica não vai se preocupar mais, de maneira central, com a ortopedia funcional dos corpos e condutas individuais, mas sim com uma atuação mais globalizante, massificada. Foucault (2010b) nos diz que enquanto a disciplina se ocuparia do homem-corpo, esta nova forma de poder, o biopoder, voltaria seu olhar para o homem-espécie. Desta forma, vemos se instalar um conjunto de processos que visam perscrutar as taxas de nascimento e mortalidade, medições demográficas variadas, controle de doenças etc. Com base no biopoder, delineia-se então toda uma biopolítica.

Essa biopolítica lida com um novo corpo: não mais o das condutas individualizadas, mas um corpo múltiplo ou multiplicado a inúmeras faces - emergindo daí a noção de população. Essa nova tecnologia não se concentrará tanto nos detalhes das condutas dos corpos considerados isoladamente, mas aperfeiçoará mecanismos globais para a manutenção do equilíbrio e regularidade dos processos biológicos, impondo sobre estes últimos não uma disciplina, mas uma regulamentação, que se expressa cada vez mais no "fazer viver", na maneira de viver, e no "como" da vida (FOUCAULT, 2010b), gerindo-a segundo os critérios mais eficazes de controle e previsibilidade. Neste cenário, disciplina e biopoder se sobrepõem e se complementam. $\mathrm{O}$ fato de atuarem em níveis distintos e de formas diferentes faz com que estas duas técnicas estejam presentes numa atuação em conjunto.

Fractal, Rev. Psicol., v. 31 - n. 3, p. 328-337, 2019
Em meio a isso, o que importa destacar é que, no atravessamento entre o disciplinar e o regulamentador, passa a situar-se, de uma forma muito geral, um novo elemento que permitirá aperfeiçoar ainda mais esta junção:

[...] pode-se dizer que o elemento que vai circular entre o disciplinar e o regulamentador, que vai se aplicar, da mesma forma, ao corpo e à população, que permite a um só tempo controlar a ordem disciplinar do corpo e os acontecimentos aleatórios de uma multiplicidade biológica, esse elemento que circula entre um e outro é a "norma" (FOUCAULT, 2010b, p. 212).

E é no alvorecer de uma sociedade de normalização que vemos o lento surgimento e consolidação de um campo crucial: a emergência da medicina moderna como ferramenta central, aos poucos cunhada como construção de saber-poder inerente às estratégias de uma nascente biopolítica. Talvez possamos afirmar que é principalmente neste campo, dentre tantos outros também importantes, que se dá a privilegiada junção do aspecto disciplinar do corpo e do regulamentador da população.

Ainda neste cenário, pensamos se não haveria expressão maior desta junção e normatividade que o campo da medicina mental, da psiquiatria ou, de forma mais geral, o dos “saberes psi” (incluindo-se aí a psicologia).

De posse do violão quebrado, já finalizando seu batuque improvisado, o homem se levanta do banco e decide sentar na calçada. Com as pernas um pouco bambas, ele se agacha com dificuldade, para logo abandonar-se ao impulso que o projeta comicamente em direção ao chão morno.

E então, depois de algum silêncio, diz: "doutor, tomo tanto remédio há tanto tempo. Já não era para eu estar curado?". À pergunta segue-se o silêncio, aos poucos quebrado, lá no fundo, por buzinas de automóveis e risos de criança.

$O$ “doutor” não diz nada.

E então o homem sorri. E com uma das mãos batucando no violão velho, pergunta: lembra de alguma música do Roberto Carlos?

Teixeira (1996) tece importantes reflexões sobre o percurso histórico que coloca sob a batuta médica a gestão social e jurídica desta nova personagem que passa a fazer parte da cena contemporânea - o "louco". Ele aponta como a psiquiatria moderna nasce com o mandato social de lidar com a loucura e dar conta dela, conceitualizando-a e dotando-a de uma "materialidade científica" que por si só seria capaz de fazê-la enquadrar-se aos procedimentos e roteiros dos demais campos de especialidade médica.

Essa "materialidade" aplicada vai sendo consolidada ao longo da história, desde os princípios da medicina classificatória do século XVIII até uma das primeiras grandes sistematizações modernas do campo psiquiátrico, promovida pelo médico alemão Emil Kraepelin, que, segundo Teixeira (1996), inspira até hoje certas correntes da psiquiatria tradicional.

De uma forma geral, o que se vê desde o início da emergência dos saberes e verdades sobre a loucura é uma gradual intensificação de um enfoque sobre possíveis causalidades biológicas, com o recrudescimento, no século XX, de abordagens neuroquímicas que, de acordo com seus re- 
presentantes mais radicais, aproximaria a psiquiatria de suas congêneres especialidades médicas pela via de uma "cura para a loucura", aqui já entendida como "doença mental”.

Todo este percurso nos serve para reiterar o que Teixeira (1996) classifica como uma visão fundada em uma permanente ideia de que haveria uma causalidade única subjacente aos fenômenos associados ao que se entende como loucura. É como se pudéssemos impor uma única chave de interpretação aos fenômenos que se associam a ela, tratando-a como um epifenômeno, isto é, "expressão manifesta de uma essência oculta" (TEIXEIRA, 1996, p. 72) que, no caso, abarcaria desordens biológicas.

Uma visão "epifenomênica", se assim pudermos falar, pode se apresentar no contexto não apenas de uma visão organicista, biológica, como ainda em tantas abordagens que buscam, pelo pensamento de uma causalidade linear, encontrar as essências ou verdades escondidas dos fenômenos da vida, sejam de ordem orgânica, social, política etc.

Trata-se de operações dotadas de um reducionismo essencialista que podem ocorrer no interior de variados discursos e que no âmbito da saúde mental podem assumir as roupagens mais diversas, inclusive em certas formas de atuação no campo da psicologia, que não muito raramente procuram as "causas" unidimensionais, essencializadas, no âmbito de uma determinada ideia de "inconsciente", "dinâmica familiar" etc.

E assim vamos reforçando os grandes blocos de saber que, atuando conforme seus ideais de controle e normalização, esmaecem as potências estéticas do viver junto. Neste cenário brevemente pinçado, quais seriam as possibilidades de abertura de espaços, respiros de um silêncio que precede outras possibilidades de vida?

Aqui poderíamos utilizar algumas pistas deixadas por Amarante (2010), inspirado inequivocamente no pensamento de Franco Basaglia. ${ }^{2}$ Ele reforça a máxima basagliana de colocar a "doença mental" entre parênteses para que nos concentremos nas existências concretas que a vivenciam enquanto tal. Desta forma, os esforços de análise se concentram não em torno da "doença" e suas causalidades, mas sobre aquilo que se construiu ao redor dela e que se apresenta como vivência (e também violência) cotidiana, suas condições de emergência histórica e tudo aquilo que vem acoplado a ela: o cárcere, o estigma, o manicômio.

Com isso, não se trata de desqualificar os saberes envolvidos na história dos fenômenos ligados à loucura, mas de abrir o campo de possibilidades para uma atuação complexa que busca afirmar a vida, afetando-se e modificando-se junto a esta, dizendo "sim" ao exercício que possa, quem sabe, ampliar fronteiras e modificar as paisagens do que temos sido até agora.

Tal é o caminho proposto por uma desinstitucionalização. Uma empreitada, segundo Amarante (2010), que não visa apenas ao enfrentamento da violência manico-

\footnotetext{
${ }^{2}$ Franco Basaglia (1924-1980), psiquiatra italiano cujo legado consiste em uma das maiores contribuições no campo das práticas em saúde mental. Um dos idealizadores do movimento da Psiquiatria Democrática, Basaglia atuou ativamente no desmantelamento de estruturas manicomiais, notadamente as das regiões de Gorizia e Trieste, na Itália, inspirando o restante do mundo em torno de suas práticas expressamente contrárias ao encarceramento da loucura nos terrenos material e simbólico dos saberes totalizantes (AMARANTE, 2010).
}

mial ou à criação de um aparato de cuidados alternativo ao isolamento asséptico da hospitalização, mas ao incitamento de uma desconstrução permanente e radical dos saberes que visam controlar, totalizar e apagar as experiências singulares e as trocas imprevistas, construindo as barricadas em face da experiência que transtorna e transforma, em favor de uma vida sempre referenciada aos códigos frios de suas já conhecidas finalidades.

E depois disso tudo talvez seja possível não responder, mas tangenciar a indagação do homem da calçada. Abrir espaço para uma desconstrução da loucura como "doença mental", alicerçada nos reducionismos de que já falamos, é também a desconstrução absoluta da ideia de "cura" que, ainda segundo Amarante (2010), tem legitimado o isolamento, a medicalização irrefletida, a tutela e a desqualificação de vidas, de nós mesmos.

As pistas possíveis para esta desconstrução se encontram, quem sabe, na busca por caminhos compartilhados, por interferências e olhares que abram espaço para algo que talvez ainda não possamos nomear, mas que se insinua logo à "esquina" para aqueles que se disponham a olhar.

Dois amigos cansados decidem repousar por alguns instantes na calçada não muito longe de casa. Despreocupados, na rua quase deserta, eles contemplam o céu nublado e se refrescam com a brisa da chuva que se aproxima. Então, pelas costas, os dois ouvem o barulho de trincos de portão se abrindo. De dentro de uma casa sai então uma senhora de cabelos brancos e vestido de algodão muito leve, esvoaçando tons de verde e vermelho sobre a calçada cinza.

Ela oferece um copo d'água. Os dois aceitam. Alguns instantes depois a mulher retorna com copos e jarra de água fresca. Saciados, eles agradecem. Em cordial silêncio, a mulher se retira.

De lá de dentro de sua casa, ouve-se em tom de criança: "vó, quem eram aqueles dois esquisitos?" e a mulher responde, paciente: "os rapazes da casa da esquina".

Sobre os dois "rapazes" já se fazia chuva, trovoada.

Este "objeto" laboriosamente cunhado - a "loucura" - nada mais é do que uma face de nós mesmos. E é somente com um trabalho sobre nós mesmos, sobre nossas existências concretas, que talvez consigamos alargar os intervalos possíveis nos incansáveis discursos que embargam vozes e respiros com suas imensas verdades, não deixando espaço vivo, quase nunca, para uma canção do Roberto Carlos cantada no meio-fio.

Assumindo este desafio, algumas ferramentas nos ajudam a pensar. Recuperando brevemente a forma de elaboração deste trabalho, destacamos o papel da pesquisa-intervenção, na medida em que ela assume um caráter aberto, favorecendo discussões e produção cooperativa a partir da relativização dos lugares de saber instituídos, abrindo espaço para a possibilidade de um trabalho compartilhado (ROCHA; AGUIAR, 2003) em meio ao plano no qual a pesquisa se desenvolve (o que inclui os atores sociais, bem como o conjunto de matérias heterogêneas que constituem uma rede vivente - o tempo, os saberes, valores, mídias etc.). 
Deste modo, quebrar a tirania dos blocos e resistir à totalização dos saberes é o desafio que se impõe. Ainda assim, como abrir espaço para que isso aconteça em meio aos endurecimentos operados por nós mesmos? As "pistas" para esse problema podem estar em simples e imprevisíveis desvios ou ainda, no mais surreal dos acontecimentos. Retornemos, pois, à conversa entre os sofás...

Em meio à conversa que se produzia entre os sofás, ouve-se uma porta abrindo. De dentro de outro comodo sai um homem curvado, de cara feia e pouca conversa. Sem cerimônia, ele abaixa as calças no meio da sala e defeca. "Que horror!", exclama uma convidada; "minha nossa senhora!", diz outra. Então, como que num passe de mágica, uma simpática mulher chega munida de balde, pano e sabão: limpa tudo em poucos segundos. Então, o carrancudo mal-humorado solta uma gargalhada, fala, pergunta qualquer coisa. E vai embora.

Rodrigues e Souza (1991, p. 39) nos dizem: “Analisador: acontecimento, indivíduo, prática ou dispositivo que revela, em seu próprio funcionamento, o impensado de uma estrutura social (tanto a não conformidade com o instituído como a natureza deste mesmo instituído)." A partir do que nos ensinam as autoras, arriscamos afirmar que o corpo que entra na sala, tira as calças e defeca produz uma inflexão nos modos de estar ali, fazendo passar outros afetos: o nojo, a surpresa, o riso...

A polarização estreita entre um sofá e outro vai cedendo lugar ao espanto que esse analisador, digamos, escatológico, produz nos corpos ali presentes. E, a partir deste fato inesperado, pegando carona nele, pode ser possível acessar outras paisagens daquela experiência que antes se limitava à circunscrição precisa de lugares cômodos, conhecidos, delimitados por especialidades. Reforçar lugares de saber em bloco, estanques, é também expressão de uma captura de aberturas possíveis, fechando-as em suas categorias pré-moldadas, seus quadros de referência, trabalhando em prol de uma transcendência que reafirma os pressupostos de uma biopolítica cada vez mais capilarizada. Por "transcendência" entendemos todo um conjunto de práticas que insistem em referenciar a vida a disposições normativas anteriores à experiência dos corpos. Falamos aqui de uma "moral" necessariamente exterior aos movimentos e encontros produzidos no plano de um cotidiano vivo. Este último muito mais ligado a uma perspectiva "ética" que se distancia das oposições estáticas entre "bem" e "mal" para se concentrar nos "encontros" e seus efeitos sobre os corpos afetados.

Em referência ao pensamento de Espinosa, Deleuze (2002) dirá que um bom ou um mau encontro não depende de um quadro de referências estabelecido a priori, mas é inerente ao próprio encontro, à própria força da experiência. O "bom encontro" é aquele capaz de aumentar a potência do corpo afetado, potência entendida aqui como força de perseverar na existência, enquanto que o "mau encontro" seria aquele que resulta em uma diminuição desta mesma potência. Ainda segundo Deleuze (2002), seguindo inspiração inequivocamente espinosista, a lei (ou, em nosso caso, a produção de verdades totalizantes) é sempre a instância transcendente, fria, que determina e codifica a "experiência" dentro dos quadros de uma moral externa às políticas que tecem o agora.

Falamos mais acima de uma biopolítica, mas talvez ainda seja preciso qualificar um aspecto maior de seu exercício sobre a vida. Isto porque até agora não fizemos menção a um aspecto crucial do conceito de "poder", no qual também se insere o biopoder de que falávamos anteriormente. Machado e Lavrador (2010) nos dizem que a noção de poder nos escritos de Michel Foucault assume um sentido muito diferente de uma acepção, quase sempre habitual, de um modo de sujeição ou constrangimento direto sobre um corpo. Uma dinâmica como esta caracteriza muito mais uma violência do que propriamente o exercício de um poder considerado como categoria complexa.

Esta visão nos adverte que o poder não está “contido", "materializado" em um dos polos de uma equação dual. O poder não é uma matéria a ser possuída e controlada; ele é, isto sim, correlações de forças em constantes enfrentamentos, incansáveis lutas. Portanto, o poder só é pensado e "pensável" a partir de relações difusas, capilares, anônimas, a todo tempo presentes, mas jamais localizáveis em essência.

Estamos falando de relações de poder. Ainda segundo Machado e Lavrador (2010), neste campo não podemos falar em termos de relações puras entre "opressores" e "oprimidos". Isto porque ao poder não se pode reivindicar uma posse ou uma localização precisa, ele permeia um campo social com seus grupos, pessoas, instituições, elementos materiais e imateriais. O poder é difuso.

E é justamente aí que reside um dos aspectos mais importantes de sua natureza. Em sendo difuso, ele não se permite capturar nos polos da equação dual "dominantes x dominados", pois seu exercício, ao contrário de uma violência coercitiva, implica sempre um espaço de liberdade. Isto acontece porque sua sustentação não se dá sobre alvos inertes ou "objetos" passivos. Em seu exercício há sempre rebatimentos, reapropriações, usos imprevistos, resistências, as quais constituem necessariamente a outra face do poder. Nestes "intervalos" possíveis, bolsões de sentido portadores de uma certa dose de liberdade, podemos antever as fronteiras de uma configuração de forças, abrindo-nos para os pontos de inflexão capazes de rearranjar as figuras de nossa própria finitude.

Não se trata de confronto ou de exclusão entre poder e resistência e sim de um jogo complexo: a resistência é condição de existência do poder e seu suporte permanente, enfim, se não há resistência resta apenas a coerção pura e simples da violência. A resistência seria o limite permanente do poder ou seu ponto de inversão. Poder e resistências são irredutíveis e, ao mesmo tempo, indissociáveis (MACHADO; LAVRADOR, 2010, p. 129).

Resistir, é preciso lembrar, não é necessariamente atuar conforme oposições dialéticas entre categorias já dadas, naturalizadas, e também não significa apenas opor recusas, buscar culpados, "julgar" o lado bom ou ruim de uma história. Resistir implica, muito mais, uma busca por pistas capazes de nos deslocar dos modos de existên- 
cia que temos colocado em funcionamento, um deslocamento de nós mesmos que envolve um "sujar-se" com as matérias do mundo, permitir afetar e ser afetado por tudo aquilo que pode diferir radicalmente das figuras já conhecidas ou re-conhecidas no espelho de nossas certezas.

\section{Conclusão: de casa para o meio-fio}

No contexto de uma biopolítica, as tecnologias de poder têm cada vez mais investido sobre a vida e sobre as formas de vida, enquadrando, classificando, contendo em barricadas a diferença que escorre à revelia de uma consciência imediata.

É, contudo, sobre a própria vida e seus modos de expressão que podemos tecer as linhas de um outro porvir, linhas que resistem e que se apropriam de imagens em fragmentos, cacos, ruínas das grandes construções do saber e da história que repetimos como tagarelas. Neste caminho não há em absoluto garantias de "sucesso", mas a fina imagem, aberta e colorida, de um compromisso ético-estético-político.

E diante deste desafio talvez seja necessário pegar carona nos acontecimentos imprevistos e às vezes cômicos de um cotidiano vivo. Retornemos mais uma vez à nossa sala de "estar"...

Após o "vexame" no meio da sala, uma das convidadas diz que não pode mais ficar. As outras também decidem ir embora. Todas se levantam, movendo-se numa coreografia lenta, hesitante, em direção à porta de saída. Aquela dança segue pela varanda da frente, vai se estendendo até o portão; eu e alguns outros também nos deixamos levar. Ali, na calçada gasta, um transeunte se detém e puxa assunto. Outras conversas e outros ares. As mulheres, antes silenciosas, começam a falar, falar sobre tudo. Nós, antes quase envergonhados, falamos também. Falamos das folhas da calçada, do tempo. Dona Maria passa com o carrinho de compras cheio de hortaliças; seu Zé passa apressado e cumprimenta com um sorriso; a criançada da escola atravessa a rua fazendo alvoroço. Uma hora é pouco no meio-fio... O tempo passa sem que vejamos. E eis que, inesperadamente, vemos um desconhecido se aproximando. Ele dança no meio da rua, andando de costas, abre os braços, sorri. E um de nós diz: "esse ai é mais doido que eu".

O meio-fio é testemunha de um movimento diferente daquele que relatamos entre os sofás. Na coreografia lenta dos que se levantam e andam em direção à rua há uma sensação diferente, uma fluidez de corpos e afetos que vão traçando caminhos comuns. Era impossível estar imune àquela dança: foi necessário dançar também.

E nos passos que levavam até a rua foram sendo diluídas as posições estanques da sala de estar; e na dança dos corpos até o meio-fio outra espécie de afetos foi tomando o corpo deste que escreve. Ao invés de uma atenção seletiva e limitada aos blocos tiranos, representando lugares pré-moldados e falas enrijecidas pela repetição do mesmo, opera-se uma abertura que lança os atores deste encontro no acompanhamento de um processo ou de um cultivo que se faz como criação estética, performance montada entre os terrenos conhecidos de nossas identi- dades e as linhas múltiplas que puxam estas últimas além se si próprias, numa cartografia de regiões ainda por vir (DELEUZE; GUATTARI, 2011).

Uma performance que se dá "entre" casa e rua, no meio-fio. Na precariedade de uma calçada gasta, fazendo caber ali outros mundos: o mundo das crianças que voltam da escola, do vizinho que passa apressado, da Dona Maria e suas hortaliças, ou do desconhecido "louco" que caminha de costas, contra a corrente.

Por fim, é com estas figuras que propomos experimentar um outro mundo possível: violões sem cordas, surpresas na sala, meios-fios, e ainda: movimentos hesitantes e vagarosos, que levam para além da razão manicomial e das verdades puras que jazem tranquilas, alheias ao tempo que as produz. Movimentos que partem do interior de uma casa, na esquina de afetos e possibilidades, e vão se fazendo feito uma dança. Dança para o meio-fio, dança para Fora.

\section{Informações sobre os autores:}

\section{Mario Cesar Carvalho de Moura Candido (iD) https://orcid.org/0000-0002-4704-6693 (9) http://lattes.cnpq.br/9526407256366809}

Possui graduação em Direito pela Universidade Federal do Espírito Santo (2008) e em Psicologia pela Faculdade MULTIVIX (2013). É mestre pelo Programa de Pós-Graduação em Psicologia Institucional (PPGPSI) da Universidade Federal do Espírito Santo, com trabalho voltado para o campo da atenção psicossocial no âmbito da saúde mental, com ênfase na interface entre processos de subjetivação, cotidiano, exercício de políticas públicas e desinstitucionalização. Cursa doutorado no departamento de Pós-graduação em Psicologia da Universidade Federal Fluminense (UFF), na linha de pesquisa Subjetividade, Política e Exclusão Social.

\section{Maria Cristina Campello Lavrador \\ (iD) https://orcid.org/0000-0002-5919-8037 \\ (9) http://lattes.cnpq.br/5508084483522992}

Graduação em Psicologia pela Universidade Santa Úrsula, Especialização em Saúde Pública pela Fundação Oswaldo Cruz, Mestrado em Psicossociologia de Comunidades e Ecologia Social pela Universidade Federal do Rio de Janeiro e Doutorado em Psicologia pela Universidade Federal do Espírito Santo. Professora Adjunta do Departamento de Psicologia e do Programa de Pós-Graduação em Psicologia Institucional/PPGPSI da Universidade Federal do Espírito Santo/UFES. Atua na área de Saúde com ênfase em Políticas de Saúde Mental: modos de subjetivação na contemporaneidade, reforma psiquiátrica, desinstitucionalização da loucura e atenção psicossocial.

\section{Rafaela Gomes Amorim \\ iD https://orcid.org/0000-0002-5158-1488 \\ (9) ttp://lattes.cnpq.br/3514625639451536}

Graduada em Psicologia (2010) pela Universidade Federal do Espírito Santo (Ufes), Mestra em Psicologia Institucional (2014) pelo Programa de Pós-Graduação em Psicologia Institucional da Ufes e Especialista em Gestão de Redes de Atenção à Saúde (2017) pela Escola Nacional de Saúde Pública ? Fundação Oswaldo Cruz (ENSP-Fiocruz). Militante na Saúde Mental pelo Núcleo Estadual da Luta Antimanicomial do Espírito Santo. Conselheira do Conselho Estadual dos Direitos da Mulher do Espírito Santo (CEDIMES) nas gestões 2012-2015 e 2015-2018, estando na função de março de 2014 a dezembro de 2017, representando o Sindicato dos Psicólogos do Espírito Santo (Sindpsi-ES), e a partir de janeiro de 2018, representando o Fórum de Mulheres do Espírito Santo. 


\section{Contribuições dos autores:}

Mario Cesar Carvalho de Moura Candido foi responsável pela coleta, análise e interpretação dos dados da pesquisa, tendo sido também responsável pela concepção e desenho do estudo, revisão e aprovação da versão final do artigo. Maria Cristina Campello Lavrador participou da coleta, análise e interpretação dos dados do estudo. Rafaela Gomes Amorim participou da coleta, análise e interpretação dos dados do estudo.

\section{Como citar este artigo:}

\section{ABNT}

CANDIDO, Mario Cesar Carvalho de Moura; LAVRADOR, Maria Cristina Campello; AMORIM, Rafaela Gomes. De casa para o meio-fio: pequenas histórias de uma residência terapêutica. Fractal: Revista de Psicologia, Niterói, v. 31, n. 3, p. 328-337, set./ dez. 2019. https://doi.org/10.22409/1984-0292/v31i3/5665

\section{APA}

Candido, M. C. C. M., Lavrador, M. C. C., \& Amorim, R. G. (2019 Setembro/Dezembro). De casa para o meio-fio: pequenas histórias de uma residência terapêutica. Fractal: Revista de Psicologia, 31(3), 328-337. doi: https://doi.org/10.22409/1984-0292/v31i3/5665

\section{Referências}

AMARANTE, Paulo. O homem e a serpente: outras histórias para a loucura e a psiquiatria. Rio de Janeiro: Fiocruz, 2010.

BENJAMIN, Walter. Magia e técnica, arte e política. São Paulo: Brasiliense, 1985. Coleção Obras Escolhidas.

BRASIL. Ministério da Saúde. Residencias terapêuticas: o que são, para que servem. Brasília: Ministério da Saúde, 2004.

DELEUZE, Gilles. Espinosa: filosofia prática. São Paulo: Escuta, 2002.

DELEUZE, Gilles. Os intelectuais e o poder: conversa entre Michel Foucault e Gilles Deleuze. In: FOUCAULT, Michel. Microfísica do poder. São Paulo: Graal, 2010. p. 69-78.

DELEUZE, Gilles; GUATTARI, Félix. Mil Platôs: capitalismo e esquizofrenia. São Paulo: Editora 34, 2011. v. 1.

FERREIRA, Marcelo Santana. Walter Benjamin e a questão das narratividades. Mnemosine, Rio de Janeiro, v. 7, n. 2, p. 121 133, jan./jul. 2011. Disponível em: https://www.e-publicacoes. uerj.br/index.php/mnemosine/article/view/41479. Acesso em: 22 maio 2016.

FOUCAULT, Michel. História da sexualidade: o cuidado de si. São Paulo: Graal, 1985. v. 3.

FOUCAULT, Michel. Michel Foucault, uma entrevista: sexo, poder e a política da identidade. Verve, v. 3, n. 5, jan./jul. 2004. Disponível em: https://revistas.pucsp.br/verve/article/ viewFile/4995/3537. Acesso em: 2 jun. 2016.

FOUCAULT, Michel. Microfísica do poder. São Paulo: Graal, 2010 a.

FOUCAULT, Michel. Em defesa da sociedade. 2 ed. São Paulo: Martins Fontes, 2010b.

FOUCAULT, Michel. A escrita de si. In: MOTTA, Manoel Barros da (Org.). Ética, sexualidade, politica. 3 ed. Rio de Janeiro: Forense Universitária, 2012. Coleção Ditos \& Escritos, v. 5 , p. $141-157$.
MACHADO, Leila Domingues; LAVRADOR, Maria Cristina Campello. As políticas que incidem sobre a vida. Estudos e pesquisas em psicologia, v. 10, n. 1, p. 118-133, jan./abr. 2010. Disponível em: http:/www.revispsi.uerj.br/v10n1/artigos/pdf/ v10n1a09.pdf. Acesso em: 2 jun. 2016.

ROCHA, Marisa Lopes da; AGUIAR, Katia Faria de. Pesquisaintervenção e a produção de novas análises. Psicologia Ciência e Profissão, Brasília, v. 23, n. 4, p. 64-73, out./dez. 2003. http:// dx.doi.org/10.1590/S1414-98932003000400010

RODRIGUES, Heliana de Barros Conde; SOUZA, Vera L. A análise institucional e a profissionalização do psicólogo. In: KAMKHAGI, V. R.; SAIDON, Osvaldo (Org.). Análise Institucional no Brasil. 2. ed. Rio de Janeiro: Rosa dos Tempos, 1991. p. 27-45.

ROLNIK, Suely. Pensamento, corpo e devir: uma perspectiva ético/estético/política no trabalho acadêmico. Cadernos de Subjetividade, São Paulo, v. 1, n. 2, p. 241-251, 1993. Disponível em: http://www4.pucsp.br/nucleodesubjetividade/ Textos/SUELY/pensamentocorpodevir.pdf. Acesso em: 7 jun. 2016.

TEIXEIRA, Manoel Olavo Loureiro. Algumas reflexões sobre o conceito de cura em psiquiatria. Cadernos do IPUB, v. 3, n. 2, p. 67-76, 1996. 